\title{
Giant insulinoma: report of a case and review of published reports
}

\author{
Kazumitsu Ueda* (D), Tetsuro Taira, Hiroyuki Hakoda, Shoko Nakata, Shinya Okata, Takeshi Nagai, Shigeo Aoki, \\ Hideyuki Mishima, Akihiko Sako, Tsunehiko Maruyama and Minoru Okumura
}

\begin{abstract}
Background: Larger insulinomas are reportedly more likely to be malignant; however, their biological behavior has not been clearly elucidated. We here report the characteristics and treatment of a giant insulinoma with local invasion and lymph node metastasis. We also review published reports concerning the clinical features of giant insulinomas and comparing their grading with that of pancreatic neuroendocrine tumors.

Case presentation: A 71-year-old man was referred to our hospital for investigation of persistent hypoglycemia. On the current presentation, laboratory tests showed serum glucose, immunoreactive insulin, and $\mathrm{C}$ peptide concentrations of $45 \mathrm{mg} / \mathrm{dL}, 17.2 \mu \mathrm{lU} / \mathrm{mL}$ and $4.1 \mathrm{ng} / \mathrm{mL}$, respectively. Dynamic magnetic resonance imaging showed a hypervascular tumor measuring $13.5 \mathrm{~cm}$ in the head of the pancreas. Computed tomography scanning demonstrated local invasion and lymph node involvement. He thus had Whipple's triad, which is associated with malignant insulinoma. No distant metastases having been identified, pancreaticoduodenectomy was performed. Intraoperatively, three separate tumors were identified in the pancreatic head. Pathological examination showed all three tumors were pancreatic neuroendocrine tumors; the tumor cells in the largest mass were strongly immunoreactive for insulin. The Ki-67 index was $2-5 \%$ in most parts of the largest tumor and over $20 \%$ in the poorly differentiated areas. This tumor was classified as neuroendocrine carcinoma in accordance with the 2010 World Health Organization classification of pancreatic endocrine neoplasms. He remains free of evidence of recurrence 2 years postsurgery.

A review of published reports indicated that giant insulinomas are more malignant than smaller ones, and metastatic disease is found on presentation in $56 \%$ of patients with giant insulinomas; however, we were unable to identify any correlation between grade of pancreatic neuroendocrine tumor and biological behavior of giant insulinomas.

Conclusions: Giant insulinomas more frequently exhibit malignant behavior, such as local invasion, lymph node involvement, and liver metastasis, than smaller ones. However, there was no relationship between grade and rate of metastases or survival in this small case series. Identification of useful biological markers is necessary.
\end{abstract}

Keywords: Giant insulinoma, Malignant insulinoma, Pancreatic neuroendocrine tumor, Ki-67 index, Grade

\section{Background}

Insulinomas are the commonest functioning pancreatic neuroendocrine tumor (pNET); their estimated annual incidence being one to three cases per million [1]. Approximately $10 \%$ are multiple and approximately $5 \%$ are associated with multiple endocrine neoplasia type 1 (MEN1) syndrome [2]. Their mean size is $1.5 \mathrm{~cm} ; 24 \%$ are smaller than $1 \mathrm{~cm}, 42 \% 1-2 \mathrm{~cm}, 30 \% 2-3 \mathrm{~cm}$, and approximately $4 \%>3 \mathrm{~cm}$ [3]. Malignancy is defined by the presence of

\footnotetext{
* Correspondence: kafureyuharyo@gmail.com Department of Surgery, Hitachi General Hospital, 2-1-1 Jonan-cho, Hitachi, Ibaraki 317-0077, Japan
}

metastases, most commonly in lymph nodes or the liver; the clinical presentation characteristically does not enable differentiating benign from malignant disease [4]. Clinicopathological evidence of malignant behavior (gross local invasion or metastases) is extremely rare in insulinomas, occurring in only $5-10 \%$ of all insulinomas; thus, most can be surgically cured [2].

Larger insulinomas are more likely to be malignant [5]; however, their biological behavior has not been clearly elucidated. Some authors have defined "giant" insulinomas as $\geq 9 \mathrm{~cm}$ in largest dimension [6,7]. We here report the characteristics and treatment of a giant insulinoma with 
peripancreatic local invasion and lymph node metastasis and present a review of published reports.

\section{Case presentation}

A 71-year-old man was referred to our hospital for investigation of hypoglycemia. Two years before, he had attended the emergency department with acute-onset loss of consciousness after a traffic accident. Hypoglycemia was identified as the cause; however, because his condition had quickly improved, he was not extensively investigated and was discharged without a definitive diagnosis. Since then, he had recurrent hypoglycemia associated with impaired consciousness. In the four preceding months, his serum glucose concentrations had been less than $67 \mathrm{mg} / \mathrm{dL}$ and he had been given intravenous glucose, which resulted in gradual resolution of symptoms.

On this presentation, his serum glucose, immunoreactive insulin and $C$ peptide concentrations were $45 \mathrm{mg} / \mathrm{dL}$, $17.2 \mu \mathrm{IU} / \mathrm{mL}$, and $4.1 \mathrm{ng} / \mathrm{mL}$, respectively. MEN-1 syndrome was excluded by normal serum intact parathyroid hormone, calcium, and prolactin concentrations. He thus had Whipple's triad (symptoms known or likely to be caused by hypoglycemia, low serum glucose at the time of the symptoms, relief of symptoms when the glucose has increased to normal). To confirm the diagnosis of endogenous hyperinsulinemia caused by insulinoma, the patient underwent a supervised overnight fast during which he developed symptomatic hypoglycemia with serum glucose of $50 \mathrm{mg} / \mathrm{dL}$.

Dynamic magnetic resonance imaging showed a $13.5 \mathrm{~cm} \times 12 \mathrm{~cm} \times 8 \mathrm{~cm}$ hypervascular tumor containing necrotic areas in the pancreatic head (Fig. 1a). Magnetic resonance cholangiopancreatography showed no involvement of the pancreatobiliary systems (Fig. 1b). Computed tomography scan demonstrated a heterogenous, enhancing, partly necrotic mass partially replacing the head of the pancreas (Fig. 2a). There was no evidence of hepatic metastasis; however, local invasion of the surrounding adipose tissues and duodenum and lymph node involvement were identified (Fig. 2b). This patient's pancreatic body and tail were slender, measuring $2 \mathrm{~cm} \times 1.5 \mathrm{~cm} \times 5 \mathrm{~cm}$; no other tumors were identified in them (Fig. 2c). No distant metastases having been identified; extended pancreatic resection was performed.

Intraoperatively, one bulky tumor and two additional undiagnosed tumors were identified in the head of the pancreas. Manual palpation by an experienced surgeon revealed no tumor in the pancreatic body and tail. One $3.5-\mathrm{cm}$ diameter pedunculated lesion was suspended from the surface of the uncinate process of the pancreas, and another 2-cm diameter tumor was attached to the duodenum. The patient underwent a subtotal stomachpreserving pancreaticoduodenectomy.
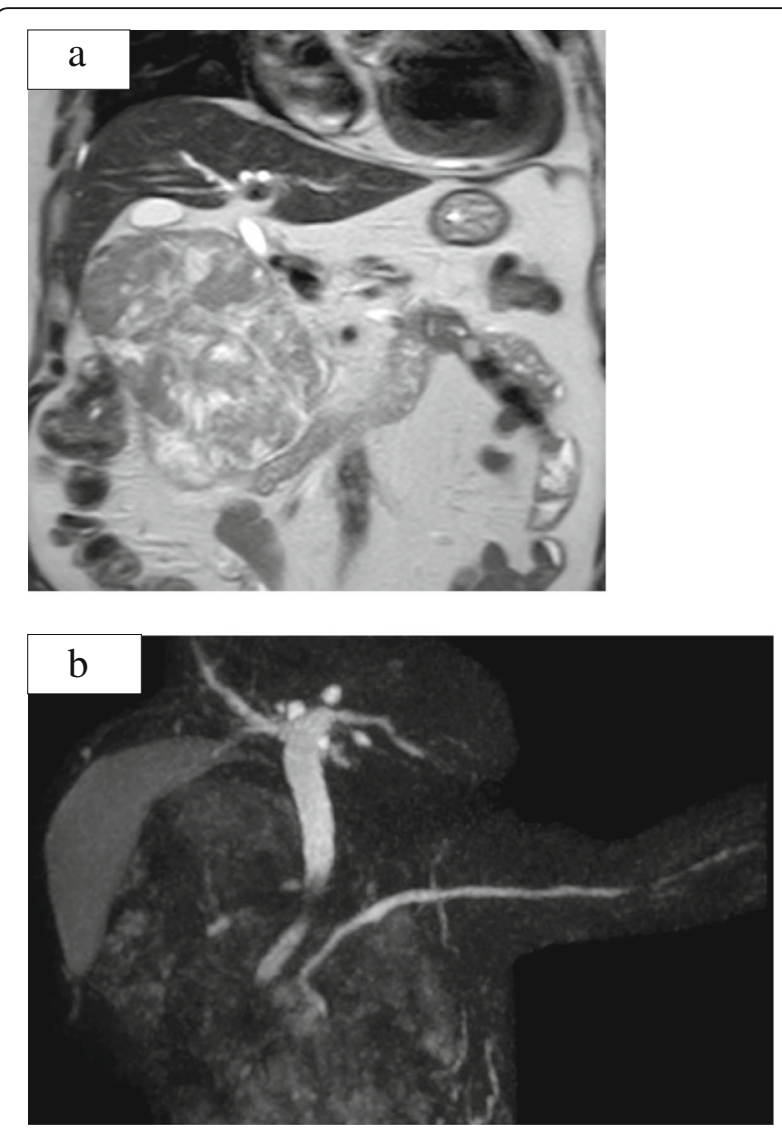

Fig. 1 Dynamic magnetic resonance image showing a $13.5 \times 12 \times$ $8 \mathrm{~cm}$ hypervascular tumor containing necrotic areas in the pancreatic head (a). Magnetic resonance cholangiopancreatography showing no evidence of involvement of pancreatobiliary trees (b)

Macroscopically, the largest tumor measured $15 \times 9 \times$ $9 \mathrm{~cm}$ and was firmly adherent to the retroperitoneum (Fig. 3a). Cut sections showed a solid lesion with evidence of hemorrhage (Fig. 3b). All three tumors were composed of uniform bland cuboidal cells with granular eosinophilic cytoplasm and round nuclei. Most of the largest mass comprised well-differentiated tumor cells (Fig. 4a); however, poorly differentiated tumor cells were identified in a small part of it (Fig. 4b). The retroperitoneal fat tissues and duodenum were involved, and metastases were identified in two of four peripancreatic lymph nodes. Immunohistochemically, the tumor showed strong diffuse expression of chromogranin $\mathrm{A}$, insulin, and glucagon and weak expression of somatostatin. The Ki-67 index was $2-5 \%$ in most of the largest tumor (Fig. 4c) but over $20 \%$ in the poorly differentiated areas (Fig. $4 \mathrm{~d}$ ). This tumor was classified as a NEC in accordance with the 2010 World Health Organization (WHO) classification of pancreatic endocrine neoplasms.

Postoperatively, a moderate pancreatic fistula developed. This resolved with conservative treatment and he was discharged on postoperative day 35. At a routine 


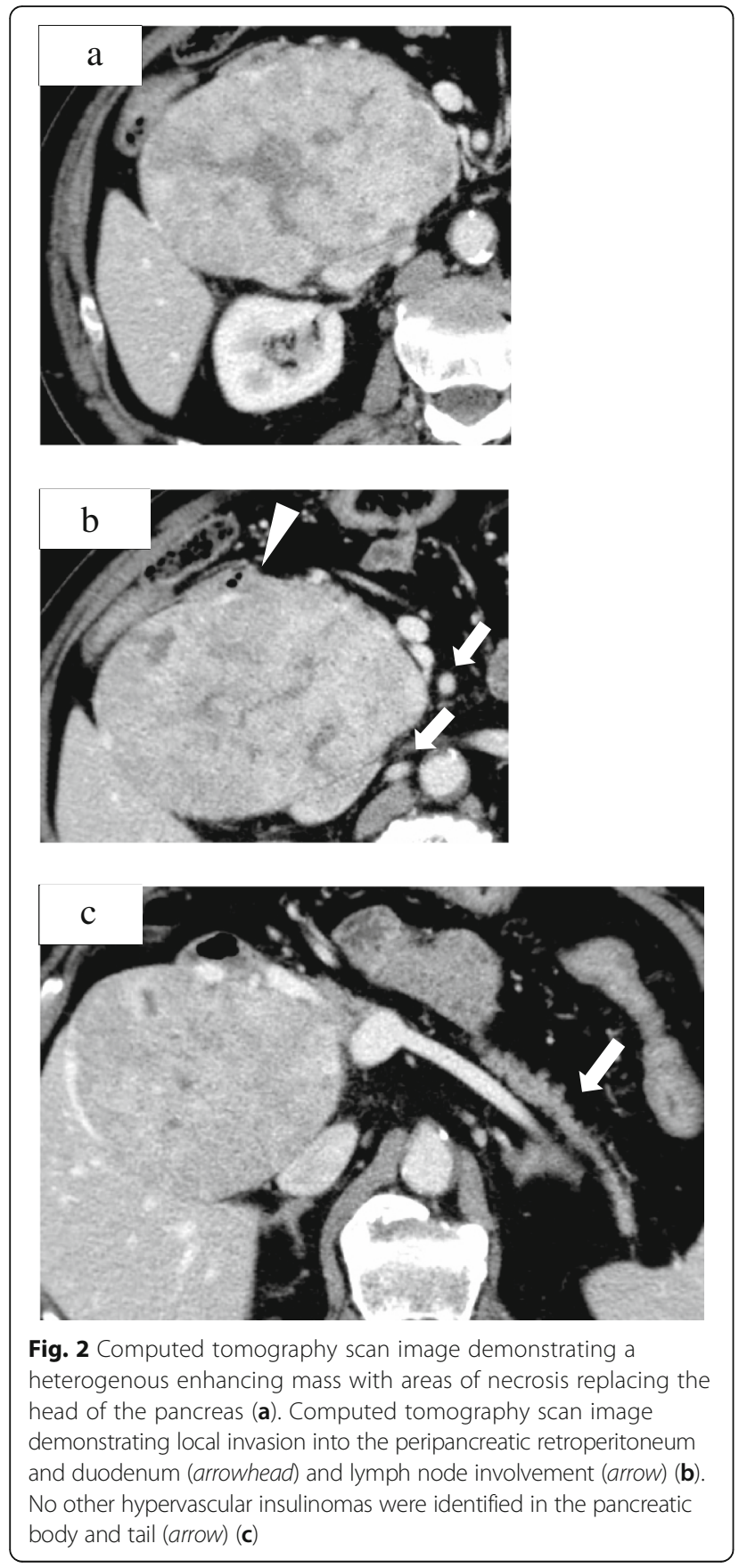

follow-up visit 3 months postoperatively, he reported no hypoglycemic symptoms, and he remains free of evidence of recurrence 2 years and 3 months after surgery.

\section{Discussion}

Because it has been difficult to differentiate between benign and malignant insulinomas on the basis of histologic findings, malignant insulinomas have been diagnosed based on metastasis to liver, lymph nodes, or other organs [2]. However, the new 2010 "WHO Classification of Tumors of the Digestive System" considers all insulinomas of
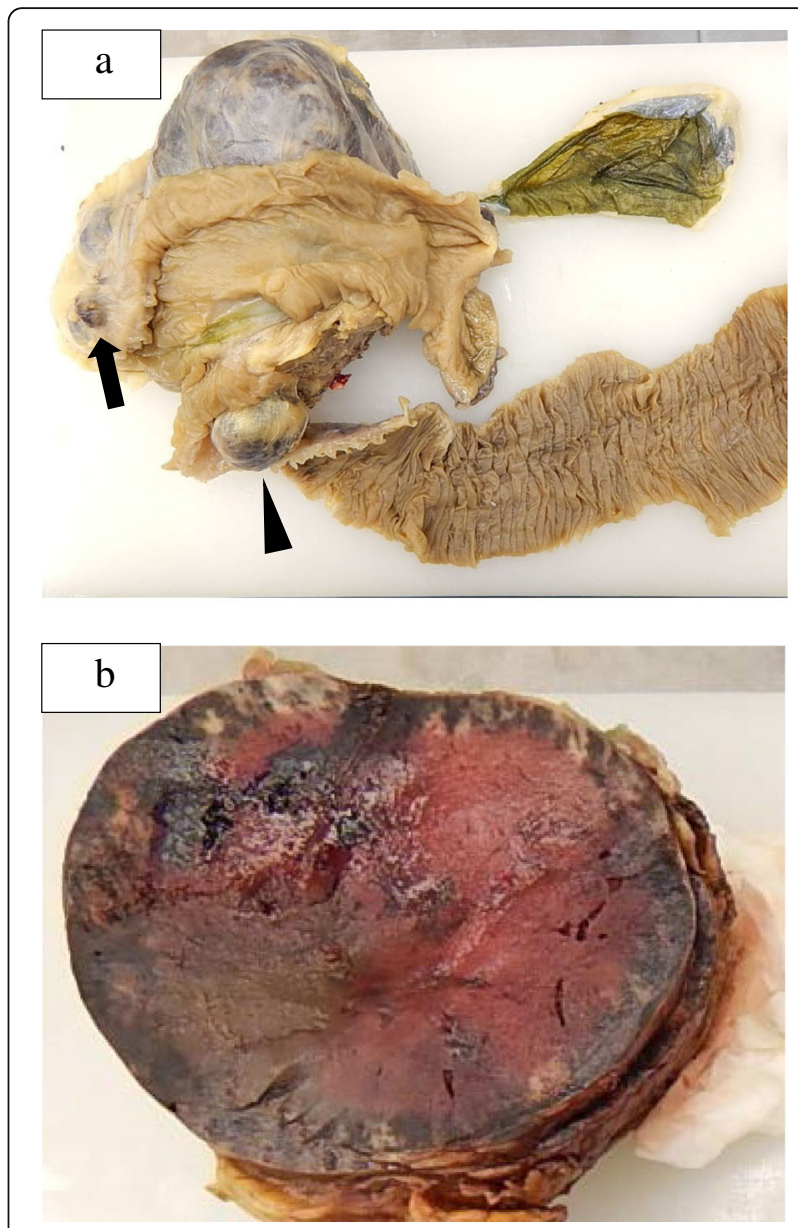

Fig. 3 Macroscopic findings. Three separate tumors are present in the head of the pancreas, namely, the largest, which was firmly adherent to the retroperitoneum, a $2 \times 2 \mathrm{~cm}$ tumor, which was adherent to the duodenum (arrow), and a $3.5 \times 2.5 \mathrm{~cm}$ pedunculated tumor that was suspended from the surface of the uncinate process of the pancreas (arrowhead) (a). The largest mass measured 15 $\times 9 \times 9 \mathrm{~cm}$ and the cut surface showed solid tissue with hemorrhagic areas (b)

$0.5 \mathrm{~cm}$ or greater malignant tumors [8]. According to the 2010 European Neuroendocrine Tumor Society guidelines, the most critical prognostic factors are the proliferative rate (mitotic index or Ki-67 labeling index) and the presence of distant metastases [9].

Surgery is the only potentially curative treatment for malignant insulinoma diagnosed at a locally advanced stage [10]. The median disease-free survival after curative resection is 5 years; recurrence occurs in more than $60 \%$ of patients at a median interval of 2.5-3 years [2]. Patients with distant metastases from insulinomas to the liver, bone, and lymph nodes have a median survival of $<2$ years [11].

Callacondo et al. [12] reviewed 35 cases of giant insulinoma and reported that they are more likely to be malignant than non-giant insulinomas; however, the relationship between clinical features, pNETs grading, and G1/G2/ NECs has not been elucidated. In all, we reviewed 45 cases 


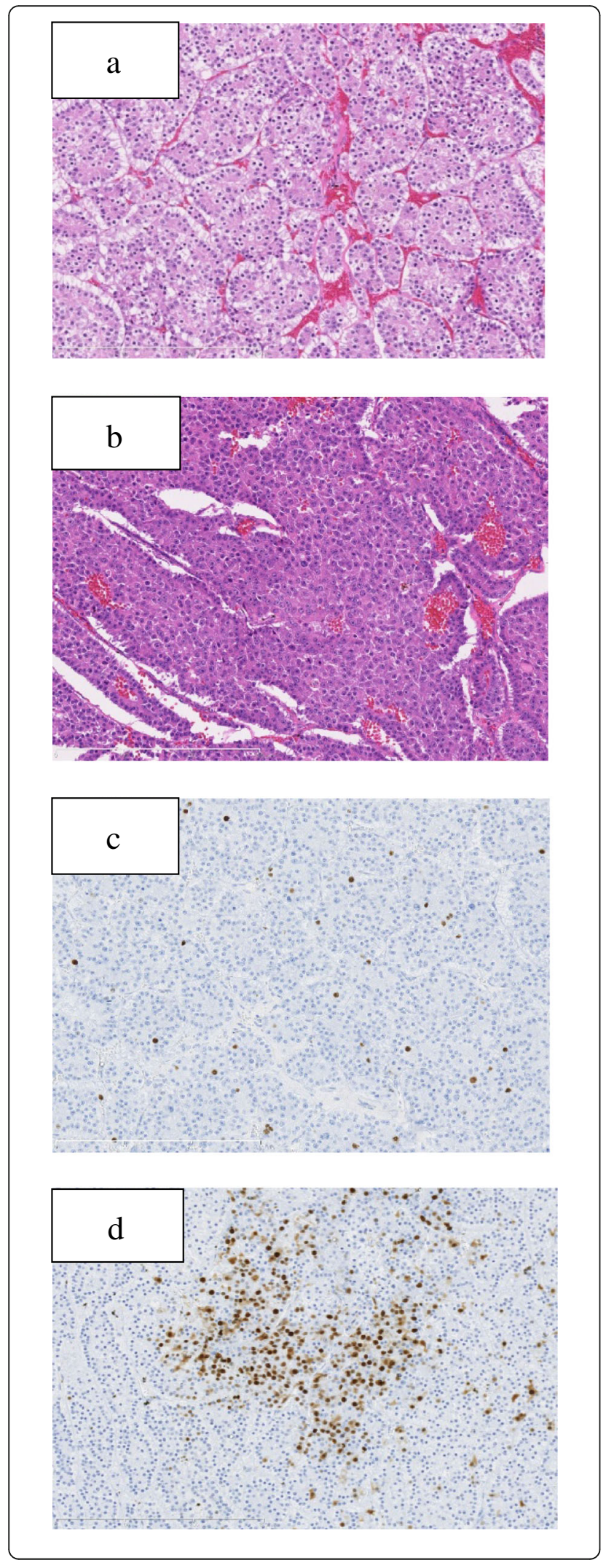

Fig. 4 Well-differentiated tumor cells were observed in most parts of the tumor (a): however, poorly differentiated tumor cells were identified in a small proportion of it (b). The Ki67 index was 2-5\% in most of the tumor (c); however, the poorly differentiated area had a Ki67 of over $20 \%$ (d)

of giant insulinoma comprising the 35 cases of Callacondo et al., an additional 9 cases $[4,5,13-19]$ and the present case (Table 1). We also investigated the relationship between recurrence rates and grade in reported cases (Table 2). We performed a PubMed search and Japanese MEDLINE databases (during the period of 1975-2015) using the keywords: "giant insulinoma," "malignant insulinoma," and "pancreatic neuroendocrine tumor" and limited our review to reports in English- and Japaneselanguage publications, including case reports.

The mean age at presentation of the 45 patients with giant insulinoma was 57 years (range, $15-83$ years), and

Table 1 Clinical features of 45 reported pancreatic giant insulinomas

\begin{tabular}{ll}
\hline Variables & \\
Age (mean) & $15-83$ (57) years \\
Sex (M:F) & $1.14: 1$ \\
Tumor diameter (mean) & $9-21(12) \mathrm{cm}$ \\
Location & \\
H/HB/B/BT/T/HBT/NA & $3 / 1 / 2 / 13 / 22 / 1 / 3$ \\
Treatment for primary disease & \\
DP (+/- S)/DP+ RLM/DP+ ALM & $23 / 2 / 2$ \\
PD/TP/E/TR/biopsy/NO/NA & $3 / 1 / 1 / 4 / 3 / 5 / 1$ \\
Metastatic sites & \\
Generalized/liver/LN, surround & $6 / 7 / 12$ \\
Recurrences/remnant/none & $8 / 11 / 26$ \\
Recurrent sites & \\
Generalized/liver/local & $2 / 4 / 1$ \\
Treatment of recurrences or remnant & \\
Surgery/Syst chemo/HACE/RT/none/NA & $3 / 2 / 2 / 2 / 1 / 7$ \\
Outcome ( $n$ ) & Duration of follow-up \\
No disease recurrence (24) & (mean) months \\
Alive with disease (6) & $3-276(18)$ \\
Died of metastatic disease (10) & $15-204$ (48) \\
Died of other disease (1) & $1-156(24)$ \\
NA (4) & NA \\
\hline
\end{tabular}

$H$ head, $H B$ head and body, $B$ body, $B T$ body and tail, $T$ tail, $H B T$ head, body and tail, NA not available, DP distal pancreatectomy, +/- with/without, $S$ splenectomy, $R L M$ resection for liver metastases, $A L M$ ablation of liver metastases, $P D$ pancreaticoduodenectomy, TP total pancreatectomy, $E$ enuclation, TR tumor resection, Biopsy biopsy of pancreatic or liver tumor, NO no operation, Generalized involvement of the liver and one or more of the following organs: adrenal glands, spleen, stomach, and colon, LN lymph node, Surround surrounding tissue, Remnant remnant disease, Syst chemo systemic chemotherapy, HACE hepatic arterial chemoembolization, $R T$ radiation therapy 
Table 2 Clinicopathological features and grade of giant insulinomas in reports published since 2001

\begin{tabular}{|c|c|c|c|c|c|c|c|c|c|c|c|c|}
\hline Author [ref]/year & Age & Sex & Size $(\mathrm{cm})$ & Location & Surgery & Ki-67 (\%) & Mitosis & Differentiation & Grade & Meta site at diagnosis & Recurrences & Follow-up (months) \\
\hline Konno [14]/2001 & 40 & $\mathrm{~F}$ & 10.5 & Tail & $\mathrm{DP}, \mathrm{S}$ & $<2$ & NA & NA & 1 & None & None & NDR (24) \\
\hline Mittendorf [6]/2005 & 65 & $\mathrm{~F}$ & 9 & Tail & Tumor resection & $>2$ & $<1$ & W & 2 & None & None & NDR (6) \\
\hline Esteban [12]/2008 & 57 & $\mathrm{~F}$ & 10 & Tail & DP & 20 & NA & W & NEC & None & None & NDR (31) \\
\hline Rega [12]/2009 & 60 & M & 15 & Body/tail & $D P, S$ & 5.4 & NA & WDEC & 2 & Surround, LN & None & NDR (3) \\
\hline Sugiyama [7]/2010 & 50 & M & 12 & Head & $\mathrm{PD}$ & $1-2$ & 1 & W & 1 & Surround & None & NDR (12) \\
\hline Matkari [12]/2010 & 32 & M & 11 & Head & E & $>2$ & NA & W & 2 & None & None & NDR (12) \\
\hline Pramodh [12]/2010 & 81 & M & 9.8 & NA & $\mathrm{NO}$ & $<5$ & NA & WDEC & 2 & None & None & DOD (NA) \\
\hline Oberheim [21]/2011 & 58 & $\mathrm{~F}$ & 13.5 & Head/body & PpPD & $<1$ & 1 & W & 1 & None & None & NDR (12) \\
\hline Callacondo [12]/2013 & 67 & $\mathrm{~F}$ & 15 & Tail & $\mathrm{DP}, \mathrm{S}, \mathrm{RLM}$ & $<1$ & $<1$ & W & 1 & Liver & Liver & $A D(60)$ \\
\hline Callacondo [12]/2013 & 63 & M & 10 & Tail & $\mathrm{DP}, \mathrm{S}$ & $<2$ & 5 & W & 1 & LN & Liver & NDR (43) \\
\hline Callacondo [12]/2013 & 38 & M & 11 & Tail & $D P, S, R L M$ & $<2$ & 3 & W & 2 & Spleen, liver & Liver & DMD (156) \\
\hline lelpo [13]/2013 & 57 & $\mathrm{~F}$ & 14 & Tail & $\mathrm{DP}$ & $>20$ & NA & Por & NEC & NA & None & NDR (72) \\
\hline Eguchi [16]/2013 & 73 & $\mathrm{~F}$ & 12 & Tail & $D P, S$ & NA & NA & NA & 1 & None & NA & NDR (4) \\
\hline Fenech [17]/2013 & 76 & $\mathrm{~F}$ & 16 & Tail & $D P, S$ & NA & $<2$ & W & 1 & Surround & None & NA \\
\hline Present case/2014 & 71 & M & 15 & Head & SSpPD & $>20$ & $>20$ & Por & NEC & Surround, LN, duodenum & None & NDR (24) \\
\hline Karavias [5]/2015 & 75 & $\mathrm{~F}$ & 17 & Body/tail & $\mathrm{DP}, \mathrm{S}, \mathrm{RMD}$ & NA & 10 & NA & 2 & $\begin{array}{l}\text { Lt-kidney, Lt adrenal, PALN, } \\
\text { liver, omentum }\end{array}$ & None & $\operatorname{NDR}(60)$ \\
\hline Vasikasin [18]/2016 & 15 & M & 12.5 & Tail & $D P, S$ & $1-2$ & $3-4$ & NA & 1 & None & None & NDR (6) \\
\hline Martino [19]/2016 & 49 & $\mathrm{~F}$ & 21 & Head/body/tail & Debulking & $>15$ & 15 & NA & 2 & $\begin{array}{l}\text { Surround, LN, liver, axillary, } \\
\text { and mediastinal }\end{array}$ & Remnant & $A D(36)$ \\
\hline
\end{tabular}

Ki-67 Ki-67 index, Mitosis mitoses per 10 high-power fields, Meta Site metastatic sites, DP distal pancreatectomy, S splenectomy, NA not available, W well-differentiated neuroendocrine tumor, NDR no disease recurrence $N E C$ neuroendocrine carcinoma, WDEC well-differentiated neuroendocrine carcinoma, Surround surrounding adipose tissue, $L N$ lymph node, $P D$ pancreaticoduodenectomy, E enuclation, NO no operation, DOD died of other disease, $P$ PPD pylorous-preserving PD, RLM resection of liver metastases, $A D$ alive with disease, DMD died of metastatic disease, Por poorly differentiated neuroendocrine tumor, SSpPD subtotal stomach-preserving PD, PALN para-aorta LN, Debulking total pancreatectomy with splenectomy, partial gastrectomy, and cholecystectomy, RMD resection of metastatic diseases, Remnant remnant liver, axillary, and mediastinal metastases 
there was a slight male preponderance (male/female ratio, 1.14:1). Those patterns are similar to those of non-giant insulinomas.

Tumor location within the pancreas was available for 42 patients. Tumors in a single segment of the pancreas had a predilection for the tail $(n=22)$; involvement of both the body and tail was seen in 12 patients. Giant tumors occur more frequently in the body and tail of the pancreas because they can grow freely there without causing mass effects or mechanical obstruction [12]. Even huge masses in the head of the pancreas rarely present with gastric outlet obstruction or obstructive jaundice because insulinomas generally enlarge slowly and do not massively invade adjacent vital organs.

Surgical resection had been performed in 36 (81.8\%) of all cases studied; the procedures comprising distal pancreatectomy (combined with resection or ablation of hepatic metastases) in 23 (4) cases, pancreaticoduodenectomy in 3 , tumor resection in 5 , and total pancreatectomy in 1 case. No patient had undergone combined resection and reconstruction of the portal vein or hepatic artery. Complete resection should be performed; however, removing $90 \%$ of the tumor is acceptable. Surgery is justified for functional advanced neuroendocrine tumors, the aims being to control symptoms, improve quality of life, and extend survival rate compared with conservative treatment [19]. Seven of 19 patients with metastases or recurrence had received sequential multimodal therapy (systemic chemotherapy, chemoembolization, ablation, and resection of liver metastases). These aggressive therapies can prolong the survival of patients with malignant insulinoma, even in the presence of liver metastases [20].

The diameter of these patient's tumors ranged between 9 and $21 \mathrm{~cm}$ (median, $12 \mathrm{~cm}$ ). Most insulinomas become symptomatic when very small, allowing early detection and prompt surgical treatment, possibly before they can metastasize. The severity of hypoglycemia varies from patient to patient and has no direct relationship with tumor burden [10]. Sugiyama et al. [7] suggested that giant insulinoma initially diagnosed as non-functioning pNETs may secondarily become functioning.

Twenty-five (55.6\%) of the cases of giant insulinoma reviewed had metastases at presentation, this percentage being higher than the $10 \%$ reported in most insulinoma series [2]. At the first surgery, six patients had involvement of the multiple organs, seven had liver metastases only, and 12 had locally advanced disease such as invasion of the surrounding adipose tissues or/and lymph node involvement. Eight cases had developed recurrences, the major site of metastases being the liver.

Follow-up data were available for 41 of the published cases. Duration of follow-up of 24 cases who had no recurrences ranged between 3 months and 23 years (median 18 months). Seven cases of the 11 fatal cases were reported before 1980. The overall survival of all patients who died with disease ranged between 1 month and 13 years (median, 2 years), whereas patients of non-giant malignant insulinoma with distant metastases had a median survival of $<2$ years [11]. Six cases alive with disease had been followed-up for 15 months to 17 years (median, 4 years).

Since 2001, the mitotic activity, Ki-67 index, and grade have been reported for 17 patients with giant insulinomas (Table 2) [5-7, 12-14, 16-19, 21]. We compared the grade, the rate of metastases and duration of follow-up of 18 cases, including the present case. The Ki-67 index was $<2 \%$ in eight cases; the only three cases with a Ki67 index of $\geq 20 \%$ were diagnosed as having NECs. Four, three, and one patient had no metastases from G1/G2/ NEC at surgery, respectively, whereas four, four, and one had synchronous metastases, respectively. Unexpectedly, there was no difference in proportion of G1/ G2/NEC in patients with versus without synchronous metastases. The median durations of follow-up by grade were as follows: 12 months (G1), 12 months (G2), and 31 months (NEC); the duration of follow-up for NECs being longer than expected. We anticipated that patients with giant insulinoma and higher Ki-67 indexes would have worse prognoses; however, we identified no relationship between grade and survival. In our small case series, we were unable to identify any correlation between grade and biological behavior of giant insulinomas.

\section{Conclusions}

Giant insulinomas more frequently exhibit malignant behavior, such as local invasion, lymph node involvement, and liver metastasis, than smaller ones. Metastatic disease is present at surgery in $56 \%$ of cases of giant insulinoma. Unexpectedly, there was no relationship between grade of pNET and rate of metastases or survival in this small case series. Identification of useful biological markers is necessary, as is development of anti-tumor agents for liver metastases.

\section{Authors' contributions \\ $\mathrm{KU}$ and TM performed the operation. KU, TT, HH, SN, SO, TN, SA, HM, AS, TM, and $\mathrm{MO}$ were involved in the treatment of the patient. $\mathrm{KU}$ and $\mathrm{TT}$ prepared the manuscript conducted the literature search. All authors read and approved the final manuscript}

\section{Competing interests}

The authors declare that they have no competing interests.

\section{Consent for publication}

Written informed consent was obtained from the patient for publication of this case report and all accompanying images.

Received: 10 August 2016 Accepted: 11 November 2016 Published online: 19 November 2016 


\section{References}

1. Vanderveen K, Grant C. Insulinoma. Cancer Treat Res. 2010;153:235-52.

2. de Herder WW, Niederle B, Scoazec J-Y, Pauwels S, Klöppel G, Falconi M, et al. Well-differentiated pancreatic tumor/carcinoma: insulinoma. Neuroendocrinology. 2006;84:183-8

3. Pasieka JL, McLeod MK, Thompson NW, Burney RE. Surgical approach to insulinomas: assessing the need for preoperative localization. Arch Surg. 1992;127:442-7.

4. Ferrer-Garcia JC, Gonzalez-Cruz VI, Navas-DeSolis S, Civera-Andres M, Morillas-Arino C, Merchante-Alfaro A, et al. Management of malignant insulinoma. Clin Transl Oncol. 2013;15:725-31.

5. Karavias D, Habeos I, Maroulis I, Kalogeropoulou C, Tsamandas A, Chaveles I, et al. Giant malignant insulinoma. Ann Surg Treat Res. 2015;88:289-93.

6. Mittendorf EA, Liu YC, Mcheny CR. Giant insulinoma: case report and review of the literature. J Clin Endocrinol Metab. 2005:90:575-80.

7. Sugiyama T, Kouyama R, Tani Y, Izumiyama H, Akashi T, Kishimoto S, et al. Giant malignant insulinoma which developed from a non-functioning pancreatic tumor over a long period of time. Inter Med. 2010;49:1573-9.

8. Rindi G, Arnold R, Bosman FT, Capella C, Klimstra DS, Klöppel G, et al. Nomenclature and classification of neuroendocrine neoplasms of the digestive system. In: Bosman FT, Carneiro F, Hruban RH, editors. WHO classification of Tumors of the Digestive System. Lyon: IARC; 2010. p. 13-4.

9. Klimstra DS, Modlin IR, Coppola D, Lloyd RV, Suster S. The pathologic classification of neuroendocrine tumors: a review of nomenclature, grading, and staging system. Pancreas. 2010;39:707-12.

10. Baudin E, Caron P, Lombard-Bohas C, Tabarin A, Mitry E, Reznick Y, et al. Malignant insulinoma: recommendations for characterization and treatment. Ann Endocrinol. 2013;74:523-33.

11. Danforth Jr DN, Gorden P, Brennan MF. Metastatic insulin-secreting carcinoma of the pancreas: clinical course and the role of surgery. Surgery. 1984;96:1027-37.

12. Callacondo D, Arenas JL, Ganoza AJ, Rojas-Camayo J, Quesada-Olarte J, Robledo H. Giant insulinoma. A report of 3 cases and review of the literature. Pancreas. 2013;42:1325-34.

13. lelpo B, Caruso R, Ferri V, Quijano Y, Duran H, Diaz E, et al. Giant pancreatic insulinoma. The bigger the worse? Report of two cases and literature review. Int J Surg Case Rep. 2013;4:265-8.

14. Konno F, Miura K, Kawarai S, Sawa N, Okamoto M, Abe K, et al. A case of giant insulinoma with physical and mental growth deficiency [in Japanese]. Geka Chiryo. 2001;84:373-7.

15. Mori R, Misuta K, Matsuyama R, Hasegawa S, Natori S, Hasegawa S, Nakano A, et al. A case of islet cell tumor with wide invasion to the spleen [in Japanese]. Jpn J Gastroenterol Surg. 2004;37:1438-42.

16. Eguchi T, Miyauchi S, Ueno Y, Kiyochi H, Matsukage S. A large insulinoma in a patient with postoperative hyperglycemia due to decreased insulin: a case report [in Japanese]. J Jpn Diab Soc. 2013;56:775-80.

17. Fenech VA, Ellul P, Abela A, Caruana C, Cassar M, Laferla G. A rare finding of a rare disease. A case report of a giant insulinoma. Pancreas. 2013;42:1195-6.

18. Vasikasin V, Watthanatham J, Napatharatip P, Temmathurapoj S. Giant insulinoma in a 15-year-old man: a case report. Int J Surg Rep. 2016;24:135-8.

19. Di Martino M, Garcia Sanz I, Delgado Valdueza J, Martin-Perez E. Giant malignant insulinoma. J Gastrointest Surg. 2016;20:1530-1.

20. Okabayashi T, Shima Y, Sumiyoshi T, Kozuki A, Ito S, Ogawa Y, et al. Diagnosis and management of insulinoma. World J Gastroenterol. 2013;19:819-37.

21. Oberheim NAE, Kim A, Farkas RL, Ruan DT, Schoeniger LO, Schiffhauer LM, et al. Giant pancreatic tumor with clinical characteristics of insulinoma but without common pathologic features. Endocr Pract. 2011;17:e12-6.

\section{Submit your manuscript to a SpringerOpen ${ }^{\circ}$ journal and benefit from:}

- Convenient online submission

- Rigorous peer review

- Immediate publication on acceptance

- Open access: articles freely available online

- High visibility within the field

- Retaining the copyright to your article 